\title{
Objectivity in contexts: withholding epistemic judgement as a strategy for mitigating collective bias
}

\author{
Inkeri Koskinen $^{1}$ (D)
}

Received: 1 November 2019 / Accepted: 26 March 2020 / Published online: 12 April 2020

(c) The Author(s) 2020

\begin{abstract}
In this paper I discuss and develop the risk account of scientific objectivity, which I have recently introduced, contrasting it to some alternatives. I then use the account in order to analyse a practice that is relatively common in anthropology, in the history of science, and in the sociology of scientific knowledge: withholding epistemic judgement. I argue that withholding epistemic judgement on the beliefs one is studying can be a relatively efficient strategy against collective bias in these fields. However, taking into account the criticisms presented against the strategy, I also argue that it is a usable strategy only when the distance between the researchers and their ideas, and the people and ideas being studied, is significant enough.
\end{abstract}

Keywords Scientific objectivity · Epistemic risk · Values in science · Collective bias - Objectivity in the social sciences - Objectivity in the humanities

\section{Introduction}

Much of the philosophical literature on scientific objectivity is based on the dismissal of one or another of two important accounts of objectivity. According to the first, scientific knowledge is objective when it grasps the objects as they really are, independently of us. The second identifies scientific objectivity with the absence of non-epistemic values at the central stages of scientific knowledge production. Both accounts have been thoroughly criticised. However, abandoning them has left us with a plethora of different, conceptually distinct notions of objectivity, each of which seems to have normative force and be useful in some context-and without a satisfactory way to explain why they all are notions of objectivity. After Heather Douglas's influential analysis of the situation (2004, 2009), many philosophers of science have agreed that

$凶 \quad$ Inkeri Koskinen

inkeri.koskinen@tuni.fi

1 Philosophy, Faculty of Social Sciences, Tampere University, and TINT, Centre for Philosophy of Social Science, Kanslerinrinne 1, 33014 Tampere University, Finland 
instead of attempting to develop a single, coherent philosophical account of scientific objectivity, we should either focus on distinguishing different, context-sensitive notions of objectivity, or as Ian Hacking (2015), for instance, has suggested, renounce the whole notion.

However, as I have recently argued (Koskinen 2018), the diverse context-sensitive, "applicable" senses of objectivity recognised in the recent literature can be covered with a single, essentially descriptive account: when we call something objective, we say that we rely on it, and that others can safely do so too, because important epistemic risks arising from our imperfections as epistemic agents have been effectively mitigated or averted. All the senses of objectivity discussed in the recent literature identify either some risk of this type, or some efficient strategy for averting or mitigating one or more such risks.

This "risk account" represents objectivity as a contextual matter: our diverse imperfections as epistemic agents lead to diverse epistemic risks, some of which become important in some contexts, and other ones in others. Moreover, the risk mitigation strategies we use must also vary according to context, as not all strategies are efficient everywhere.

As the editors of this topical collection have noted, not much attention has yet been paid to social research in the recent literature on objectivity in science. So in this paper I focus on a certain strategy developed and used in the humanities and qualitative social sciences, contrasting it to strategies developed in the natural sciences. As Daston and Galison (2007) note, objectivity has historically been strongly linked to the duty of scientists to avoid subjectivity. Strategies developed with this aim in mind typically screen out the subjective biases and idiosyncrasies of individual researchers. However, such strategies are not efficient against collective bias-that is, situations where an entire research community shares some biased view, possibly without anyone realising the situation. I will argue that the strategy of withholding epistemic judgement has been adopted in anthropology, in the sociology of scientific knowledge, and in the history of science, in order to mitigate ethnocentrism, Whig historiography, and asymmetrical explanations of successful and unsuccessful scientific theories-all perceived as collective biases. The strategy of withholding epistemic judgement reflects the perceived importance of averting or mitigating collective bias in the humanities and qualitative social sciences. But the contextual nature of risk mitigation strategies means that a strategy that is satisfactory in one context can be less satisfactory in another one, or can become unusable when the context changes. I analyse arguments presented against the practice of withholding epistemic judgement in the light of the risk account of scientific objectivity.

I will begin with an overview of the recent literature on scientific objectivity, and identify four desiderata for an applicable account of objectivity. Then I discuss positive and negative accounts of objectivity, and present and defend the risk account of scientific objectivity. Finally I use it to analyse the practice of withholding epistemic judgement as a strategy for mitigating collective bias in anthropology, history of science and the sociology of scientific knowledge. 


\section{Applicable senses of scientific objectivity}

Let me start from two distinct, influential understandings of scientific objectivity: objectivity as grasping the objects, and objectivity as value-freedom. According to the first view, objectivity has an ontological and an epistemic aspect: objective knowledge tells about things as they are out there in the world, independent of us (Axtell 2016; Reiss and Sprenger 2017). This view has been thoroughly criticised. For Kantian reasons one might say that it does not even make sense, as we have no conceptual access to things except under one or another representation-that is, we have no access to things as they are completely independent of us. Or one might adopt a Foucauldian argument and point out that many knowledge claims that are taken as objective have meaning only in complex and questionable networks of social and ethical commitments, and that this destabilises the idea of their objectivity in such a strong sense. Or one might simply note that this understanding of scientific objectivity seems to presuppose a view from nowhere (Nagel 1986), which we do not have, or point to the "Really Real" (Lloyd 1995), which we cannot reach.

But much recent discussion about scientific objectivity has arisen from criticisms of the other influential account of objectivity: the value-free ideal, or in other words, the idea that in objective research, non-epistemic values do not influence the gathering of evidence or the acceptance of scientific theories. This account makes no references to the objects as they are independently of us, but it has nevertheless been denounced as unattainable, as we cannot ensure that the value-freedom of all the background assumptions on which scientists base their work (Longino 1990, 2001). Moreover, many philosophers today agree that non-epistemic value judgements can be necessary in all stages of scientific knowledge production (Dupré and Wylie 2007; Douglas 2000, 2009; Crasnow 2013).

As we really cannot ensure that scientific research or the knowledge it produces is objective in either of these two senses, and as we do not necessarily even wish them to be so, the notion of objectivity easily becomes just a rhetorical device. And indeed, precisely for this reason several philosophers, most recently Ian Hacking (2015), have suggested that philosophers should just drop the whole notion from their conceptual toolbox. It is but an elevator word used for emphasis; hand waving rather than a useful tool for philosophical purposes.

However, many philosophers still want to defend the notion as a useful one in philosophy. To do so, they (or rather, we) have developed accounts of objectivity that I call "applicable": ones that can actually be applied when trying to assess whether something — a method, a researcher, a community, etc.-is objective. Clearly the first of the two accounts described above is inapplicable; that is after all the crux of many of the criticisms against it. Therefore philosophers of science who wish to talk about scientific objectivity have largely adopted a different approach: they do not mention the ontological aspect of the notion at all. The second account has not been abandoned so thoroughly: while the value-free ideal has been largely abandoned, controlling the role of non-epistemic values in science is still an important part of the discussions about objectivity.

The emphasis on applicability has led to discussions about objectivity in different contexts. What makes research objective in fields that use statistical techniques 
differs from what makes archaeological collaborations with descendant communities objective, or what makes the science of well-being objective (Freese and Peterson 2018; Wylie 2015; Alexandrova 2018). It seems that an applicable account of scientific objectivity has to be somehow contextual. While reading recent discussions (e.g. Montuschi 2003; Douglas 2004; 2009; Crasnow 2013; Wright 2018; see also Koskinen 2018), I have outlined four desiderata that philosophers trying to defend some applicable notion of objectivity appear to largely share. They characterise a satisfactory applicable account of scientific objectivity:

1. An account of scientific objectivity should not refer to things as they are independent of us, as it would render the notion inapplicable.

2. An account of scientific objectivity should allow for fallibilism: objectivity cannot imply certainty, as we cannot ensure certainty in science.

3. In order to be an applicable notion, scientific objectivity must be a degree notion: we have to be able to say that $y$ increases or decreases the objectivity of $X$ (a theory, a community, a procedure, etc.).

4. A satisfactory account of scientific objectivity has to be applicable in various contexts: it should be of use when talking about objectivity both for instance in the context of the replication crisis in the experimental sciences, and in the context of participatory ethnography.

As Heather Douglas (2004, 2009) and Marianne Janack (2002) have noted, we can identify several senses of objectivity that are used in the philosophical literature. Many of them are "applicable" in the sense described above. For instance, procedural objectivity, where the research process has been designed so that a researcher can always be changed to another, and that will not change the result, meets the first three desiderata fairly well. So does interactive objectivity, where a research community follows practices that ensure effective critical discussions and debates. (Douglas 2004, 2009.) And as philosophers of science examine applicable criteria for assessing the objectivity of something in specific contexts, even more senses of objectivity seem to emerge. The fourth criterion is met when we take all the different senses into account: for all different contexts, there are typically several senses of objectivity that can be fruitfully applied.

According to Douglas, many of the different senses of objectivity recognised in the recent literature are conceptually distinct. They cannot be reduced to any one sense "unless one is willing to make rather strong metaphysical or epistemological presumptions" (Douglas 2004, p. 465). In other words, unless one resorts to references to the objects as they are independently of us, or something similar-which everyone is trying to avoid.

So it seems that if we give up the ontological aspect of objectivity, the notion loses an important cohesive element, and we end up with a plethora of different senses of objectivity. However, I have recently developed a descriptive account that accounts for all the recognised applicable senses of objectivity, and thus brings some unity to the notion. Before describing it in detail, I will first discuss two possible approaches towards such a unifying account. 


\section{Positive and negative accounts}

Let us distinguish between positive accounts of objectivity that refer to some epistemically advantageous elements that the things we call objective share, and negative accounts that focus on epistemically harmful elements that are missing from whatever we call objective. Some of the different applicable senses of objectivity mentioned above are positive, and some negative. Now, if we are looking for a unifying account that would cover all these different applicable senses, should we look for a positive or a negative account?

I will be defending a negative account. To clarify why, let us examine a positive alternative. In this topical collection Zahle (2020) uses a positive account that is meant to grasp the many different ways in which we in different contexts use the notion of objectivity. She refers to Thomas Kuhn's (1977) classic discussion of epistemic values and Alison Wylie's description of objectivity as "a loosely defined family of epistemic virtues that we expect will be maximized, in some combination, by the claims we authorize as knowledge" (Wylie 2003, p. 33). When focusing on the objectivity of scientific theories, such virtues include for instance empirical adequacy, internal coherence, and inferential robustness. Wylie emphasises the contextual nature of objectivity by pointing out that all the different objectivity-making properties cannot be maximized simultaneously. So the choice of the virtues that should be emphasised depends on the aims and purpose of the conducted research-which in turn depend both on value-decisions and on the context in question.

Zahle applies Wylie's positive account and develops a list of the epistemically good-making features of qualitative data sets. She argues that descriptive adequacy, reactivity transparency, deception transparency, relevance, balance, and sufficiency make qualitative data sets objective. These features are "objectivity-making characteristics"; they constitute the objectivity of an objective data set.

This kind of a positive account explains well why objectivity takes different forms in different contexts: all of the different objectivity-making properties cannot be maximized simultaneously, and in different contexts different features are deemed the most important ones. However, such a positive approach faces certain problems. It risks broadening the meaning of the notion so far that it no longer corresponds with our actual usage of it, and simultaneously rendering the notion superfluous. This is because it risks identifying scientific objectivity with anything epistemically advantageous.

For instance, if we were assessing the objectivity of research processes, we might conclude that is an epistemically good-making feature to take all available, relevant data into account. Surely such thoroughness should be on the open-ended list of epistemic virtues or features we expect to be maximized. However, if a researcher for some reason does not take all of the available, relevant data into account, we will not automatically take the omission as a sign of a lack of objectivity. There are other possible reasons for the lapse, such as ignorance. If the researcher is told about the missing data, and she then promptly takes into account, it would seem odd to claim that what was wrong in the research process was related to objectivity. So the positive account broadens the notion too far: we use the notion of objectivity only in some of the situations it covers. Moreover, if objectivity is identified with any epistemically 
good-making features, it is difficult to defend the continued use of the notion. Why not just dismiss it, as Hacking among others suggests, and simply talk about epistemically advantageous features of research, or theories, or qualitative data sets-features that make them good? If we are to defend the continued use of the notion of objectivity, we need an account that restricts its meaning more than this kind of a positive account does.

The other possible way to approach the issue, that is, negative accounts of objectivity, seems to offer the needed restrictions. A well-known example of a negative account has been presented by Daston and Galison (2007). They argue that new senses of objectivity that have emerged in science have generally been related to newly recognised threats arising from our subjectivity: objective research avoids them. Along similar lines, Hacking (2015) has recently claimed that "objective" is a negative adjective that indicates the absence of some epistemic vice, not the presence of an epistemic virtue. However, it would be odd to call collective biases of which researchers are unaware "vices", for example. So I would like to talk simply of threats-or rather risks.

\section{The risk account of scientific objectivity}

I have recently (Koskinen 2018) defended a negative account that I call the risk account of scientific objectivity: When we call $X$ objective, we say that we rely on $X$, and that others can safely do so too, because we believe that important epistemic risks arising from our imperfections as epistemic agents have been effectively mitigated or averted. ${ }^{1}$ This account brings unity to the notion: all the applicable senses of objectivity identify either an epistemic risk arising from our imperfections as epistemic agents, or a strategy for mitigating or averting one or several such risks.

The risk account brings together several ideas developed in the literature on objectivity.

Douglas (2004, 2009), following Arthur Fine (1998), argues that though all the different senses of objectivity are conceptually distinct, they do have something in common: when we call $\mathrm{X}$ objective, we say that we trust $\mathrm{X}$, and that others should do so too-objectivity indicates "a shared basis for trust in a claim" (Douglas 2009, p. 123). However, if we accept the standard distinction between trust and reliance (Baier 1986) then trust can be betrayed and reliance only disappointed. So if we want to talk about the objectivity of for instance a method, we should talk about reliance, not trust, as a method cannot betray us.

To clarify what this reliance is based on, let us turn again to negative accounts of objectivity. As noted, Daston and Galison (2007) argue that at least historically, emerging new senses of objectivity have been related to newly recognised threats arising from our subjectivity. However, subjectivity does not quite capture all the things we should avoid in order to increase the objectivity of our work. Cognitive biases and collective biases are not particularly subjective, but they do threaten scientific objectivity. So instead of talking about subjectivity, I use the notion of epistemic risks.

\footnotetext{
1 In (Koskinen 2018) I only talk about averting risks. I now believe that in many cases, though not always, the verb "mitigate" is more apposite.
} 
Biddle and Kukla (2017, p. 218) define them very broadly as "risk of epistemic error that arises anywhere during knowledge practices".

Objectivity is related to the avoidance of a specific subset of epistemic risks. We start to talk about objectivity when we face persistent epistemic risks that arise from our failings. The risks of subjectivity, idiosyncrasies, cognitive biases, collective biases etc. are important epistemic risks arising from our imperfections as epistemic agents.

It must be noted that the risk account itself is not normative in the sense that it would tell us whether some $X$ can be deemed objective. This is because it does no specify what risks of epistemic error should be seen as important or why, nor does it describe the strategies that are or should be used to mitigate or avert the risk, nor does it argue why they are effective. However, the risk account clarifies why the applicable, often context sensitive senses of objectivity have normative force: it is because they do all this. They all claim that some important epistemic risk (or several) has to be averted or mitigated, and/or that a specific strategy is efficient when trying to do so.

The word "important" is important, as it clarifies why we do not usually talk about objectivity when facing mundane epistemic risks such as simple reasoning errors or easily redeemable ignorance. It also explains many disagreements about objectivity. Researchers can differ in their assessments of the most important epistemic risks they face in some context. After all, such assessments are based on epistemic and at times also non-epistemic values, and researchers can have divergent views of their relative importance (Kuhn 1977; Douglas 2000; Wylie 2003). Moreover, researchers can also disagree about the efficacy of some suggested mitigation strategy.

The risks account meets the four desiderata mentioned in Sect. 2. Firstly, it does not refer to the ontological aspect of objectivity. Secondly, it is thoroughly fallibilistic, and allows the applicable senses it covers to be equally fallibilistic. Objectivity does not entail certainty, as our strategies for mitigating risks may fail, there may be risks we have not identified or risks against which the chosen strategy is ineffective- or something completely unrelated to objectivity may skew the results. Thirdly, the risk account makes scientific objectivity a degree notion. One or more epistemic risks can be mitigated or averted, or a strategy used for mitigating risks can be more or less effective. So it makes sense to say that we can reduce or aggravate a risk. And fourthly, the risk account clarifies why in different contexts, different applicable senses of objectivity are relevant. Many different kinds of epistemic risks arise from our various failings as epistemic agents. What is an important risk depends on the context, as different risks are particularly pressing in different contexts. Moreover, the risk account also separates epistemic risks from the strategies developed for mitigating them. As I will soon argue, many strategies are applicable only in some contexts, so different strategies are needed in different contexts.

The risk account makes strategies for averting or mitigating epistemic risks a central part of objectivity. And for the rest of this paper I will be focusing on one such strategy. One that seems to work in some contexts in the humanities and in the qualitative social sciences-but only some. 


\section{The idea of collective bias}

In philosophical discussions about objectivity, the focus is typically on risks that are important and strategies that are efficient in the natural sciences. This is the case, for instance, in what Douglas calls procedural objectivity: strategies that ensure that researcher can be changed without changing the results. It is easy to see that in procedural objectivity the focus is on the epistemic risks arising from the imperfections of individual epistemic agents. As Daston and Galison have noted, such risks have for a long time been seen as central in the natural sciences. Thus for instance experimental methods are generally designed so as to ensure procedural objectivity as far as possible.

When talking about objectivity in the humanities and in the qualitative social sciences we must focus both on strategies that can actually be used in these contexts, and on epistemic risks that are deemed particularly pressing in them. It is easy to see that in historiography or anthropology the use of experimental methods is possible only to a very limited degree. And devising other ways to ensure procedural objectivity may sometimes be impracticable. Changing an ethnographer in the middle of her fieldwork is not as simple as changing a scientist working in a laboratory. So the mitigation of the epistemic risks arising from the imperfections of individual researchers as epistemic agents has to be ensured in some other way-for instance, through critical peer discussions and debates. But these are not the only risks that are deemed particularly important in the humanities and in the qualitative social sciences. Not only individual, but also collective biases are taken very seriously in these fields.

To clarify the idea of collective bias, let us start by turning to the natural sciences and examining an example described by Haraway (1989). According to her, the study of primates in the US in the first half of the twentieth century was androcentric and sexist: all researchers shared similar ideas about human men and women, and this led to research based on male-dominance schemas. In such a situation it is fully possible that no one belonging to the research community realises the epistemic risks that the collective bias creates. If the research questions and methods used in an entire field are based on the same biased background assumptions, the overall picture drawn from the knowledge produced becomes skewed. For instance, Haraway argues that in primatology the sexist assumptions led to a situation where the many roles females play in primate groups were largely ignored. The overall picture of primate life and primate groups, based on the produced knowledge, was therefore misleading.

Strategies that are effective against individual biases are easily ineffective against collective ones. For example, strategies that ensure that a researcher can be changed without changing the results do not help: if virtually all researchers in a research community share the same biased background assumptions, changing the researcher and getting the same results does not prove the absence of bias. For instance, the research conducted in primatology in the 1950s was probably fairly objective in the procedural sense. This would not stop the collective bias from skewing the scientific understanding of primates and their behaviour. According to Haraway, only after feminist women entered the field did the situation change, as they also started to study the females. 
Let us now return to the humanities and the qualitative social sciences. In the 1950s - when primatology, according to Haraway, was still ridden with sexist bias-ethnographers, as well as historians, for instance, were already acutely aware of epistemic risks caused by collective biases. My focus here is on three fields where collective bias is perceived as a serious threat: anthropology, the history of science, and the sociology of scientific knowledge. In all three fields other peoples' ideas, thoughts and beliefs form an important part of the object of study. A collective bias can distort such study if all or most researchers in the field would agree, were they asked to assess whether the studied ideas and beliefs are convincing or plausible. To better understand why this is so, let us briefly look at each of the three fields.

In anthropology, ethnocentrism has for a century now been treated as something that seriously jeopardises the epistemic quality of research and must be avoided. Ethnocentric ethnography is based on the idea that the researcher's own culture is better than other cultures. Other cultures are seen as less developed, and should be assessed using standards of the researcher's culture. While for the nineteenth-century evolutionary anthropologists such beliefs were an important part of their theoretical commitments, their critics saw ethnocentrism as a serious collective bias to be avoided (Westermarck 1932; Benedict 1934; Boas 1940). If ethnographers base their interpretations on the assumption that their own beliefs are superior to those of their informants, they risk failing in their central attempt to understand what the informants actually believe. This is because such beliefs are properly understood only in their context. If an anthropologist compares a claim an informant makes too hastily to her own beliefs, and assesses it accordingly, the comparison and assessment can distort the often difficult task of interpreting the claim. The belief in the superiority of one's own beliefs would be a poor starting point in the task of interpreting the famous Bororo claim 'my brother is a parrot' (Crocker 1977), for example.

Whig historiography also used to be conducted more or less intentionally: historians based their work on the idea that the present is better than past, and that the past constitutes the progressive lead-up to the present. But already in the first half of the twentieth century such views were harshly criticised: Whiggish assumptions were identified as biases that distort research (Butterfield 1931; Koyré 1939). In the history of science, criticisms of Whiggism, often understood as synonymous to "presentism" or "triumphalism", arose during the latter half of the twentieth century, and were already commonplace by the 1970s. Historians of science argued that a Whiggish tendency to judge past science according to its contribution to scientific views that are held true today distorts research and leads to teleological narratives of scientific progress. (Jardine 2003; Alvargonzáles 2013.)

A similar development took place in the sociology of scientific knowledge. Particularly the scholars who formed the Edinburgh school argued that when studying scientific knowledge production, sociologists should avoid explaining the success of theories that are accepted today differently than the former success of theories that have eventually been refuted. They took such asymmetrical treatment to be seriously biased. The current status of a theory in the eyes of the scientific community should not determine the way in which a sociologist starts to study its formation. (Bloor 1976; Barnes et al. 1996.) 
In all three cases, the identified bias is of a collective nature: the critics argue that their predecessors did not fully grasp the adverse consequences of their ideas: ethnocentrism, Whiggism and asymmetrical explanations distort research, as important aspects of the results are fixed beforehand in an epistemically unjustified way. Moreover, the critics saw these biases as something whole research communities are prone to succumb to. As long as all ethnographers share a similar social and cultural background and a similar education, it is all too easy to draw on that background and education when assessing ideas developed in other cultures. In the history of science and the sociology of scientific knowledge, the risk is even more obvious: all researchers who are alive at the same time share similar ideas about which scientific theories are likely to be reliable and which have been rejected for good reasons. Unless this is actively avoided, it is natural to explain the success of the accepted theories by saying that they were the correct ones, and to either say little about the success of eventually refuted theories, or to offer social explanations. In other words, these three quite similar collective biases were in their respective fields identified as important epistemic risks arising from our imperfections as epistemic agents.

\section{Withholding epistemic judgement as a strategy for mitigating collective bias}

Not only was the risk identified, but by mid-century ethnographers already had a wellestablished strategy for mitigating collective bias: withholding epistemic judgement. ${ }^{2}$ During the latter part of the century, the same strategy would also be adopted by historians of science and sociologists of scientific knowledge.

The rationale of this strategy is simple: you will not—even inadvertently—assess the informants' beliefs or the work of early or current scientists by the standards of judgement ingrained into you through culture and education, if you altogether avoid judging these epistemically.

In ethnography the strategy translates into practices where the knowledge claims made by informants are treated in a very different way than those of one's colleagues. When encountering the first kind of claim, an ethnographer is supposed to attempt to interpret it—only the latter kind of claim may be criticised. Evaluative comparisons between knowledge systems or belief systems are avoided. Informants' cosmological views, or their stories about the origin of humankind, are not something an ethnographer would compare to the current scientific understanding of the structure of the universe or human evolution. Thus, for instance, the claim that in the autumn birds fly to lintukoto ("the home of the birds"), which they reach by slipping under the edge of the sky, is not something an ethnographer doing fieldwork in Siberia would attempt to criticise (Siikala 2002; Koskinen 2011). Such suspension of judgement and censure is

\footnotetext{
2 In anthropology the strategy would sometimes take the form of withholding not only epistemic, but also moral judgement: if the study of the moral codes accepted in different cultures can be distorted by judgements based on the ethnographer's own moral views, such judgements should be avoided. This methodological principle has often been mixed with forms of moral relativism, which in turn has been heavily debated in anthropology (see e.g. Goodale 2006). However, I will here focus on the withholding of epistemic judgement, as it is a strategy used in all three fields I examine here.
} 
quite generally seen as "co-terminous with good anthropology" (Jarvie 2006, p. 582). Critical debates occur between colleagues who "speak the same language, belong to the same academic profession, live in the same society" (Asad 1986, p. 156), and who therefore understand each other and often share more or less the same standards of epistemic judgement - all of which makes it possible for them to engage in a meaningful debate.

In the history of science and in the sociology of scientific knowledge the strategy of withholding epistemic judgement, typically called neutrality or impartiality, takes a slightly different form than in anthropology. This is because in these fields some of the ideas studied tend to sound more plausible to the researchers than others, and the perceived epistemic risks ensue from this asymmetry. As David Bloor (1981) argued in a debate with Larry Laudan, if researchers let the future success of a theory direct the way in which the development of that theory is studied, they risk missing important parts of the processes they study. The correctness of a theory does not always explain its success. For example, when Louis Pasteur questioned Félix-Archimède Pouchet's views about the possibility of spontaneous generation of life from nonliving materials, Pasteur eventually triumphed—but not because he was right. Bloor cites Farley and Geison's (1974) account of the clash, where the authors convincingly show that Pasteur's victory was largely due to political and religious reasons. So, argues Bloor (1981, pp. 200-201), a "comprehensive rather than an arbitrarily truncated picture of science" must be based on research that treats all beliefs alike.

One of the key components of the strong programme in the sociology of scientific knowledge, impartiality, translates into the practice of withholding epistemic judgement on the scientific knowledge claims the sociologist is studying: one should remain "impartial with respect to truth and falsity, rationality or irrationality, success or failure" (Bloor 1976, p. 7). Harry Collins has emphasised the methodological nature of this norm. If the aim is to investigate the part scientists have played in the construction of scientific knowledge, "it is no use using the outcome of the process as a part of the explanation of the outcome" (Collins 1981, p. 222). The best way to avoid doing so is to deliberately bracket one's "scientific instinct" or "pre-analytic intuitions" (ibid.). As Collins emphasised, this is far from easy; one can fail, in many subtle ways, to withhold epistemic judgement. Nevertheless, it is clear that he held the attempt to be a fairly effective strategy for mitigating collective bias.

\section{Limits of the strategy}

Withholding epistemic judgement may be an effective strategy for mitigating collective bias. However, this is true only in some contexts. For instance, the strategy would not have helped the primatologists in the 1950s, as it is applicable only in contexts where other people's ideas are a central part of the object of study. This is not the case in primatology, so the strategy would not have been usable: primatologists do not study anything with regards to which they could withhold their epistemic judgement. As already noted, using experimental methods that satisfy (or are supposed to satisfy) the requirements of procedural objectivity is often not a usable strategy for mitigating 
individual biases and idiosyncracies in humanities research. Similarly, withholding epistemic judgement is an unusable strategy in the natural sciences.

But the contexts where the strategy is usable are limited not only by the nature of the object of study, but also by the distance between the researchers and their ideas, and the people and ideas being studied. When the distance diminishes or is not significant enough, researchers using this strategy encounter at least two clear problems. Firstly, if the necessary distance disappears (or if the necessary distance has always been missing), the strategy becomes unusable, as it becomes inadmissible or practically impossible to actually withhold epistemic judgement. Secondly, the people whose ideas are being studied can protest against the strategy. Let us look at both problems in more detail.

Chang (2009) has recently argued that though full neutrality is often assumed to be the only way to avoid Whiggism, it has never really been a suitable strategy in the history of science. Current science is linked to past science in many ways that quite unavoidably affect the historian's problem-choices. So when historians choose their research questions, they cannot help assessing what aspects of past science are worthy of study. Chang (2009, p. 253) therefore argues that in the history of science, neutrality is "in fact a judgmental stance disguised as non-judgement".

In anthropology withholding epistemic judgement has been a usable strategy, but only as long as ethnographers have worked among communities that have little contact with Western, academic thought. In contemporary anthropology, there are researchers who prefer not to work with informants, but rather have members of the studied communities become co-researchers in participatory projects. Moreover, activist researchers belonging to Indigenous communities participate in anthropological conferences. In such situations withholding epistemic judgement is no longer a suitable strategy. Avoiding the epistemic appraisal of the knowledge claims made by a member of one's research team is hardly an epistemically advisable practice. And it would be both epistemically and ethically questionable to deny critical comments from Indigenous activist researchers (Koskinen 2014).

The people whose knowledge is being studied can also protest against the strategy of withholding epistemic judgement. For instance, they can interpret it as a sign of mistrust or disparagement - as a statement that their knowledge claims are not worthy of epistemic appraisal. Indigenous activist researchers have criticised earlier anthropology and demanded that Indigenous thought and Indigenous philosophies or epistemologies should be approached not "simply as interesting objects of study (claims that some believe to be true) but as intellectual orientations that map out ways of discovering things about the world" (Garroutte 2003, p. 10). In a surprisingly similar way scientists encountering the work of sociologists subscribing to the ideas of the strong programme have sometimes disapproved quite vehemently. While the socalled science wars certainly did not reduce to misunderstandings or disagreements about the aims and methods of the sociology of scientific knowledge, the strategy of withholding epistemic judgement can be seen as one of the bones of contention in said disputes. Some scientists either did not understand the methodological nature of the sociologists' impartiality, or they found it otherwise unacceptable, and potentially harmful, as they feared it might jeopardise public trust in science (Hacking 1999; Labinger and Collins 2001). 
But we must remember that the strategy of withholding epistemic judgement has served a purpose: it is a strategy adopted in order to mitigate a specific epistemic risk arising from our imperfections as epistemic agents: collective bias. If the strategy is abandoned, the epistemic risk must be mitigated in some other way. And, naturally, other strategies are being suggested and developed. For historians of science, Chang (2009, p. 254) offers a strategy which he calls independent judgmentalism: "the historian is a free agent, despite her/his obvious rootedness in present society and science [...] We historians need to face up the implications and consequences of the judgements we do and must make. I am much happier to accept that burden of responsibility, than to hide beneath a murky notion of neutrality." In anthropology and fields close to it, researchers collaborating with Indigenous communities, for instance, are developing negotiation techniques in order to find out shared ideas and to build on them. Nicholas and Wylie (2012; see also Tully 1995) note that the starting point of such negotiations has to be the recognition of differences, rather than an assumption of some underlying, universal framework. They focus on value differences, but such negotiation techniques can also prove epistemically useful, if they offer a way to avoid ethnocentrism without avoiding epistemic judgement.

\section{Conclusions}

Withholding epistemic judgement can be an effective strategy for mitigating collective bias, but it is needed only in some contexts, and is a usable strategy only in some contexts. The same applies to many strategies used in order to increase the objectivity of science: they are efficient against some epistemic risks, not all, and they are usable in some contexts, not all. Withholding epistemic judgement appears as a possibly useful strategy only in contexts where certain kinds of collective biases-such as ethnocentrism or Whiggism - are deemed important. There it helps the researcher to avoid the bias. But it is a usable strategy probably only when the distance between the researchers and their ideas, and the people and ideas being studied, is significant enough.

The risk account of scientific objectivity allows this kind of an analysis. It clarifies why withholding epistemic judgement can be seen as a strategy that increases the objectivity of research, and it is useful when defining the limitations of the strategy. Moreover, by drawing attention both to the variety of epistemic risks that induce us to talk about objectivity, and to the variety of risk mitigation strategies, it clarifies why objectivity is such a contextual matter.

If we wish to pay more attention to objectivity in social research, or in the humanities and the qualitative social sciences, understanding the contextual nature of scientific objectivity is crucial. The epistemic risks arising from our imperfections as epistemic agents that are deemed particularly important in these fields are not necessarily the same risks that are emphasised in the natural sciences. Moreover, the risk mitigation strategies used do not look the same at all. If this is not recognised, many strategies that arguably increase the objectivity of research in the humanities and the social sciences can go unnoticed by philosophers interested in objectivity. This would be a shame, as it could lead to misleadingly harsh assessments of the objectivity of research and its results in these fields. 
Acknowledgements Earlier versions of this article were presented in the workshop Objectivity in Social Research in Bergen in 2019, in EPSA 2019 in Geneva, and in research seminars in Helsinki and Tampere. I would like to thank the audiences in these meetings, and particularly Hasok Chang, Jani Hakkarainen, Julian Reiss, Kristina Rolin, Jan Sprenger, Jack Wright, Julie Zahle, and two anonymous referees for useful comments and suggestions. Any errors that remain are my own. Funding for this research was provided by the Academy of Finland (Grant No. 294585 and 316695).

Open Access This article is licensed under a Creative Commons Attribution 4.0 International License, which permits use, sharing, adaptation, distribution and reproduction in any medium or format, as long as you give appropriate credit to the original author(s) and the source, provide a link to the Creative Commons licence, and indicate if changes were made. The images or other third party material in this article are included in the article's Creative Commons licence, unless indicated otherwise in a credit line to the material. If material is not included in the article's Creative Commons licence and your intended use is not permitted by statutory regulation or exceeds the permitted use, you will need to obtain permission directly from the copyright holder. To view a copy of this licence, visit http://creativecommons.org/licenses/by/4.0/.

\section{References}

Alexandrova, A. (2018). Can the science of well-being be objective? The British Journal for the Philosophy of Science, 69(2), 421-445.

Alvargonzáles, D. (2013). Is the history of science essentially whiggish? History of Science, 51(1), 85-99.

Asad, T. (1986). The concept of cultural translation in british social anthropology. In J. Clifford \& G. E. Marcus (Eds.), Writing culture (pp. 141-164). Berkeley, CA: University of California Press.

Axtell, G. (2016). Objectivity. Cambridge: Polity.

Baier, A. C. (1986). Trust and antitrust. Ethics, 96, 231-260.

Barnes, B., Bloor, D., \& Henry, J. (1996). Scientific knowledge: A sociological analysis. Chicago: University of Chicago Press.

Benedict, R. (1934). Patterns of culture. Boston: Houghton Mifflin.

Biddle, J. B., \& Kukla, R. (2017). The geography of epistemic risk. In K. C. Elliott \& T. Richards (Eds.), Exploring inductive risk: Case studies of values in science (pp. 215-237). New York, NY: Oxford University Press.

Bloor, D. (1976). Knowledge and social imagery. London: Routledge \& Kegan Paul.

Bloor, D. (1981). The strengths of the strong programme. Philosophy of the Social Sciences, 11(2), 199-213.

Boas, F. (1940). Race, language, and culture. New York: Macmillan.

Butterfield, H. (1931). The Whig interpretation of history. London: G. Bell.

Chang, H. (2009). We have never been whiggish (About Phlogiston). Centaurus, 51, 239-264.

Collins, H. M. (1981). What is TRASP?: The radical programme as a methodological imperative. Philosophy of the Social Sciences, 11(2), 215-224.

Crasnow, S. (2013). Feminist philosophy of science: Values and objectivity. Philosophy Compass, 8(4), 413-423.

Crocker, J. C. (1977). My brother the parrot. In D. J. Sapir \& J. C. Crocker (Eds.), The social use of metaphor: essays on the anthropology of rhetoric (pp. 164-192). Philadelphia: University of Pennsylvania Press.

Daston, L., \& Galison, P. (2007). Objectivity. New York, NY: Zone.

Douglas, H. (2000). Inductive risk and values in science. Philosophy of Science, 67, 559-579.

Douglas, H. (2004). The irreducible complexity of objectivity. Synthese, 138(3), 453-473.

Douglas, H. (2009). Science, policy and the value-free ideal. Pittsburgh: University of Pittsburgh Press.

Dupré, J., \& Wylie, A. (Eds.). (2007). Value-free science? Ideals and illusions. Oxford: Oxford University Press.

Fine, A. (1998). The viewpoint of no-one in particular. Proceedings and Addresses of the American Philosophical Association, 72, 7-20.

Freese, J., \& Peterson, D. (2018). The emergence of statistical objectivity: Changing ideas of epistemic vice and virtue in science. Sociological Theory, 36(3), 289-313.

Garroutte, E. M. (2003). Real Indians: Identity and the survival of native America. Berkeley: University of California Press. 
Geison, G., \& Farley, J. (1974). Science, politics and spontaneous generation in nineteenth-century France: the Pasteur-Pouchet debate. Bulletin of the History of Medicine, 48(2), 161-198.

Goodale, M. (2006). Toward a critical anthropology of human rights. Current Anthropology, 47, 485-511.

Hacking, I. (1999). The social construction of what?. Cambridge: Harvard University Press.

Hacking, I. (2015). Let's not talk about objectivity. In F. Padovani, A. Richardson, \& J. Y. Tsou (Eds.), Objectivity in science: New perspectives from science and technology studies (pp. 19-33). Cham: Springer.

Haraway, D. (1989). Primate visions: Gender, race, and nature in the world of modern science. New York, NY: Routledge.

Janack, M. (2002). Dilemmas of objectivity. Social Epistemology, 16, 267-281.

Jardine, N. (2003). Whigs and stories: Herbert butterfield and the historiography of science. History of Science, 41(2), 125-140.

Jarvie, I. (2006). Relativism and historicism. In S. P. Turner \& M. W. Risjord (Eds.), Philosophy of anthropology and sociology (pp. 553-589). Amsterdam and Boston: Elsevier/North-Holland.

Koskinen, I. (2011). Seemingly similar beliefs: A case study on relativistic research practices. Philosophy of the Social Sciences, 41(1), 84-110.

Koskinen, I. (2014). Critical subjects: Participatory research needs to make room for debate. Philosophy of the Social Sciences, 44(6), 733-751.

Koskinen, I. (2018). Defending a risk account of scientific objectivity. The British Journal for the Philosophy of Science. Published ahead of print 03 August 2018. https://doi.org/10.1093/bjps/axy053.

Koyré, A. (1939). Études galiléennes. Paris: Hermann.

Kuhn, T. S. (1977). Objectivity, value judgment, and theory choice. The essential tension: Selected studies in scientific tradition and change (pp. 320-339). Chicago: University of Chicago Press.

Labinger, J. A., \& Collins, H. (2001). Introduction: The "science wars" and the "two cultures". In J. A. Labinger \& H. Collins (Eds.), The one culture? A conversation about science (pp. 1-10). Chicago and London: University of Chicago Press.

Lloyd, E. (1995). Objectivity and the double standard for feminist epistemologies. Synthese, 104, 351-381.

Longino, H. E. (1990). Science as social knowledge: Values and objectivity in scientific inquiry. Princeton, NJ: Princeton University Press.

Longino, H. E. (2001). The fate of knowledge. Princeton, NJ: Princeton University Press.

Montuschi, E. (2003). The objects of social science. London: Continuum.

Nagel, T. (1986). The view from nowhere. New York, NY: Oxford University Press.

Nicholas, G. P., \& Wylie, A. (2012). "Do not do unto others...": Cultural misrecognition and the harms of appropriation in an open source world. In R. Coningham \& G. Scarre (Eds.), Appropriating the past: Philosophical perspectives on the practice of archaeology (pp. 195-221). Cambridge: Cambridge University Press.

Reiss, J., \& Sprenger, J. (2017). Scientific objectivity. In Zalta, E. (ed.). The stanford encyclopedia of philosophy (Winter 2017 Edition). https://plato.stanford.edu/archives/win2017/entries/scientific-objectivity/.

Siikala, A. (2002). Myth and mentality: Studies in folklore and popular thought. Helsinki: Finnish Literature Society.

Tully, J. (1995). Strange multiplicity: Constitutionalism in an age of diversity. Cambridge: Cambridge University Press.

Westermarck, E. (1932). Ethical relativity. New York: Littlefield, Adams \& Company.

Wright, J. (2018). Rescuing objectivity: A contextualist proposal. Philosophy of the Social Sciences, 48(4), 385-406.

Wylie, A. (2003). Why standpoint matters. In R. Figueroa \& S. Harding (Eds.), Science and other cultures: Issues in philosophies of science and technology (pp. 26-48). New York: Routledge.

Wylie, A. (2015). A plurality of pluralisms: Collaborative practice in archaeology. In F. Padovani, A. Richardson, \& J. Y. Tsou (Eds.), Objectivity in science: New perspectives from science and technology studies (pp. 189-210). Cham: Springer.

Zahle, J. (2020). Objective data sets in qualitative research. Synthese. https://doi.org/10.1007/s11229-02002630-2.

Publisher's Note Springer Nature remains neutral with regard to jurisdictional claims in published maps and institutional affiliations. 